\title{
Oral Surgery
}

National Cancer Institute

\section{Source}

National Cancer Institute. Oral Surgery. NCI Thesaurus. Code C17174.

Surgical procedures for treating diseases and disorders of the oral cavity. 